\title{
O documentário Falcões, meninos do tráfico - testemunhos do cotidiano traumático
}

\author{
Betty Fuks', Ana Maria Rudge ${ }^{2}$
}

\begin{abstract}
Resumo
O artigo propõe uma reflexão sobre o documentário Falcões - meninos do tráfico, produzido pelo rapper MV Bill e o ex-menino de rua Celso Athayde. O testemunho das próprias crianças e adolescentes aliciadas pelo tráfico de droga, è o fio condutor de nossa indagação sobre as conseqüências trágicas da fusão entre o flagelo da miséria e o da droga. Procedemos, então, um questionamento sobre o cotidiano dos meninos à luz do conceito psicanalitico de trauma e da noção de testemunho originária da crítica literária. As contribuições de alguns psicanalistas nos permitem abordar como injunções absurdas e paradoxais, apresentadas pela realidade ambiental das nossas favelas, podem exceder a capacidade do sujeito de tolerar conflitos, encaminhando-o para a alienação que tanto a droga adiç̧ão quanto o pertencimento ao bando criminoso propiciam.
\end{abstract}

Palvras-chaves: vida nua, testemunho, criminalidade, violência e trauma

\begin{abstract}
The article presents a reflection on the film Falcons - boys of the traffic, produced by the rapper MV Bill and the former- homeless boy Celso Athayde. The testimony of the children and adolescents enticed by the drug dealers to join the traffic is the main subject of our investigation on the tragic consequences of the conjunction between extreme poverty and drugs. The daily life of those boys is analyzed under the light of the psychoanalytic theory of trauma, and the notion of testimony originated from the literary theory. The theoretical contribution of some psychoanalysts help us to approach how the absurd and paradoxical injunctions presented by the environmental reality of brazilian slums may exceed the subject's capacity to tolerate conflicts, disposing him to the alienation which both the drug addiction and joining the criminal band may propitiate.
\end{abstract}

Keywords: naked life, testimony, crime, violence, and trauma

\footnotetext{
- Professora Adjunta do Mestrado em Psicanálise, Saúde e Sociedade, Universidade Veiga de Almeida (RJ), Professora do Curso de Especialização em Psicologia Clinica - PUC-RJ, Membro do Colégio de Psicanálise da Bahia, Pesquisadora da Rede Universitária de Pesquisa em Psicopatologia Fundamental

2Professora Associada do Departamento de Psicologia da PUC-Rio, Membro Psicanalista da Sociedade de Psicanálise Iracy Doyle, Pesquisadora do CNPq. Pesquisadora da Rede Universitária de Pesquisa em Psicopatologia Fundamental
} 
Em maio de 2006 foi transmitido pelo programa Fantástico, da TV Globo, o documentário "Falcão - Os meninos do tráfico", que mostrou ao grande público, de forma inédita, a trágica situação das crianças brasileiras aliciadas pelo tráfico de droga. A obra recebeu esse nome quando os autores do documentário, Celso Athayde, exmenino de rua, e M V Bill, jovem rapper ${ }^{1}$ morador da Cidade de Deus, verificaram que a instituição dos garotos que servem como soldados para proteger o tráfico nas favelas tinha se espalhado pelas comunidades de várias regiões do Brasil: "Vimos em todas as nossas cidades os meninos encontrando no tráfico de drogas o caminho para sobreviver"(BILL, 200619/03/2006), disseram à imprensa.

Falcão é o nome dado às crianças que têm o encargo de vigiar e avisar aos cabeças do tráfico a presença da polícia ou de qualquer estranho na favela. $O$ sentimento despertado pelo filme, segundo MV Bill, é o de uma enorme tristeza com o destino desses meninos, dos quais quase todos já haviam sido mortos antes mesmo que o documentário fosse exibido. Entre os 17 entrevistados, só um escapou a esse destino, e, segundo ele mesmo, por ter sido preso. O que nos faz 60 pensar que talvez essa contingência não tenha sido o único motivo, é o fato de que o único falcão sobrevivente foi exatamente aquele que foi capaz de expressar um desejo e um projeto: “. Meu sonho é ser palhaço de circo; quando completar 18 anos, largo esta vida de bandido e me matriculo numa escola de circo"(GULAR, 2006).

De certa forma, estamos acostumamos à presença de crianças desamparadas em esquinas turbulentas, espreitando nossa "pátria mãe gentil" das negociatas, dos congressistas e até ministros que se locupletam em acordos espúrios com as empresas, como a Gautama, cujas obras superfaturadas, como as casas populares em Duque de Caxias, cujas fotos veiculadas pelos jornais, mostrando paredes rachadas, esgoto vazando pelas ruas, verdadeiras ruínas, evidenciam os efeitos do total descaso com o que é público.

Mesmo assim o filme não deixa de causar estranheza pelo teor da narrativa de cada pequeno falcão. O sentimento Unheimlich (não familiar) que Freud detectou, em sua prática clínica e na análise etimológica do termo, estar sempre junto de seu aparente oposto, Heimlich, (familiar), reverbera e ecoa em nós ao ouvir a fala dos meninos. Por um lado, cada narrativa toca diretamente em experiências psíquicas de desamparo a que já fomos submetidos. Aquilo de que 
suspeitávamos, mas sobre o que evitávamos pensar, de repente surge provocando angústia. Angústia diante da realidade dos meninos aliciados pelo tráfico e barbaramente abandonados pela sociedade organizada, em uma medida jamais conhecida.

Ao impacto da apresentação do documentário, seguiu-se um livro também chamado Falcão, em que os autores do filme relatam o dia a dia das pesquisas e filmagens, e um DVD lançado em final do ano passado, no qual foi anexada ao filme uma entrevista inédita de MV Bill, em que conta como surgiu esse projeto que abrangeu oito anos de conversas filmadas com os meninos do tráfico. Una das cenas que mais chama atenção do espectador, é a do rapper contando ter observado a satisfação dos falcões, durante as entrevistas, em ter alguém para ouvir suas narrativas. Histórias que nem mesmo às mães poderiam contar, já que muitas delas não aceitam de boa vontade que seus filhos se tomem fora-da-lei. "Eu trafico para ajudar minha mãe. Eu sei que ela não gosta, mas eu trafico para ajudar ela", diz o pequeno falcão para a câmera. A adesão dos meninos ao projeto de MV Bill e Celso Athayde ficou evidente nas ocasiões em que os pesquisadores foram chamados pelas mães de alguns jovens assassinados para participar, filmando, no enterro de seus filhos, uma vez que estas haviam percebido o quanto seus filhos consideravam importante o trabalho que estava sendo desenvolvido pela dupla.

A iniciativa de documentar a vida dos "falcões", desde dentro de seu território e através de seu próprio testemunho, da narrativa dos meninos sobre suas vidas, estabelece uma ponte entre eles, presos ao muro da pobreza, e os que não compartilham dessa realidade: "Falcão não dorme, ele só descansa", diz um deles cuja voz nos desperta.

De fato, calou fundo no coração daqueles que o ouviram o testemunho da pequena criança de 10 anos: "se eu morrer nasce um outro que nem eu, pior ou melhor". Uma sentença a pairar sobre a cabeça de todos. O "falcão" sabe o que diz: pertence, como os que vieram antes dele e os que virão depois, à parte excedente da sociedade que é reduzida à "vida nua", isto é, uma vida que não merece ser vivida, exposta à exclusão e ao assassinato, Assassinato que não tem uma conotação sacrificial, mas que é pura e simplesmente exterminio do homo sacer (AGAMBEN, 2002)ㄹ. Para o nosso pequeno "filósofobandido" de olhos tristes, a vida humana permanecerá irredutivelmente sombria enquanto for tratada desta forma, como vida eliminável. 
Desamparados pelo Estado, os "falcões" são incluídos em nossa sociedade unicamente sob a forma de sua exclusão imediata. "Quando crescer quero ser bandido". O menino que serve ao tráfico, de algum modo devolve ao remetente, à nação, sua própria mensagem de forma invertida. Desenraizado e despossuído, relegado a uma zona de indiferenciação dentro e fora do espaço jurídico-político, nada tem como projeto viável de futuro, exceto o pertencimento à quadrilha do tráfico. Os meninos vêm de um grupo formado por legiões de desassistidos, sem biografias e sem lugar em nossa sociedade. Esta é a questão que suscita um dos maiores impasses, ético e político, do Estado brasileiro.

Os falcões não têm medo nem da morte, observa Bill, com um laivo de admiração no olhar por aqueles que pouco têm a perder, e de revolta pela situação que condena o "Falcão" à vida nua. Diz um dos meninos: "se eu morrer vou descansar, esta vida é um esculacho". Testemunho contundente de quem já se sabe sem futuro, impedido de experimentar o fogo e a beleza da vida.

O teor testemunhal do vídeo e do livro nos confronta com a fala dos meninos. Observa-se, em cada narrativa, um movimento reflexivo sobre a situação em que estão mergulhados; o que nos autoriza a dizer que cada testemunho, em si mesmo, significa uma fresta que se abre no beco sem saída em que estão vivendo. MV Bill declarou na entrevista que desejou inicialmente fazer um vídeo sobre os falcões que não fosse uma ficção, isto é uma encenação sobre suas vidas, o que terminou por levá-lo a filmar e apresentar as próprias crianças envolvidas no mundo da droga. "Me colocava" conta ele no filme, "como o ouvinte dos artistas que ninguém nunca queria ouvir falar deles".

Antes de prosseguir, é preciso pensar sobre este gesto de Bill de se colocar como ouvinte dos meninos. Gesto que não é, de modo algum, estranho a nós, herdeiros de Freud. Sabe-se que a psicanálise foi fundada no momento em que o seu fundador colocou-se como ouvinte da histérica, a "artista" criadora do famoso "talking cure". À dor da histérica, Freud prescreve atenção e escuta, contrapondo-se a ciência positivista que então lhe conferia o estatuto de simuladora por contrariar os cânones da neurociência da época. A narrativa tornou-se o meio pelo qual uma paciente passou a dirigir ao outro as lembranças do trauma vivido. Portanto, o ato de se pôr como ouvinte da dor do outro, franqueia a narrativa de uma vivência traumática. "Talking cure". 
Se considerarmos que os meninos vivem em meio a uma situação extremamente traumática, na medida em que atravessam o limite da vida humana cotidianamente, podemos ousar estabelecer um diálogo entre a psicanálise e a produção artistica de Bill e Athayde através do conceito de testemunho que ganhou maior atenção da crítica literária, após a segunda etapa da "Guerra dos 30 anos" que marcou o século $\mathrm{XX}$. Usaremos o conceito como uma espécie de charneira entre aquilo que podemos definir psicanaliticamente como narrativa individual de um trauma, e a narrativa de uma "catástrofe histórica" - trauma coletivo como, por exemplo, a guerra e as situações limites de pobreza e perseguições politicas.

Márcio Seligmann-Silva em História, Memória, Literatura: o testemunho na era das catástrofes (2003) enfoca dois diferentes aspectos do conceito de testemunho. O primeiro circunscreve a literatura de testemunho da Shoah, a catástrofe do Século XX que manchou de sangue a civilização. Nestas produções, o testemunho da barbárie, com toda sua força de reatualização que comanda a relação do sujeito com o passado traumático, leva o leitor ao encontro com o real que não se deixa reduzir.

Tanto a teoria do testemunho como a teoria psicanalítica, esbarram, permanentemente, com os limites da palavra em narrar a crueldade do real. Uma face desta crueldade foi reconhecida por Freud em $O$ mal estar na civilização, como a vocação da humanidade para "satisfazer no outro a agressão, explorar força de trabalho sem ressarci-lo, usá-lo sexualmente sem o seu consentimento, humilhá-lo, infligir-lhes dores, martirizá-lo e assassiná-lo". (FREUD, S. 1930/1976, p. 116)

Anteriormente, o testemunho dos soldados que voltavam dos campos de batalha da Primeira Guerra Mundial já lhe haviam mostrado a incapacidade do sujeito traumatizado tanto de esquecer quanto de relatar a cena que, com a face da morte, se reatualiza repetidamente nos sonhos traumáticos que reconduzem o sonhador exatamente ao momento da experiência de horror.

A literatura escrita a partir de Auschwitz e que deu impulso para a discussão sobre a noção de testemunho revela o mesmo: o testemunho oferece provas da incapacidade de inscrição de um passado traumático no presente, já que visa a reatualização de algo que jamais pode ser totalmente traduzido. Para Selligman nas situações em que o 
sujeito, de uma maneira ou de outra, atravessou a "morte" a relação da linguagem com o real sempre é problemática (SELIGMANN-SILVA, 2000, P. 8).

O autor nos fala também da experiência histórica e literária do "testemonio" na América Latina. Diferentemente da literatura de testemunho da Segunda Guerra Mundial, o testemonio não chega a problematizar a questão da representação do real, e prioriza o evento testemunhal sobretudo na sua modalidade de denúncia e reportagem. Entretanto, não se pode perder de vista a semelhança entre as teorias do testemunho e do testemonio, ou seja, o teor testemunhal de ambas.

$O$ ato de testemunhar deve ser compreendido nos sentidos jurídico, histórico, e no de sobrevivência a um evento-limite radical. Neste último sentido, o testemunho é em si mesmo potencialmente terapêutico, na medida em que, narrando a cena traumática à qual se sobreviveu, o sujeito faz uma tentativa de integrar a memória do passado ao presente com vistas ao devir. A narrativa é o recurso daquele que sobrevive para elaborar o evento do trauma no sentido freudiano, uma experiência dolorosa que não se têm condições de 64 processar adequadamente, e que fica encrustada no psiquismo como um verdadeiro corpo estranho .

Por outro lado, se as teorias do testemunho se voltam principalmente para a questão de como os traumas, que se localizam no passado, podem ser retomados e traduzidos no presente, nada nos impede de reconhecer a possibilidade de que o testemunho possa ter lugar em meio às situações traumáticas ${ }^{4}$. Falcão, meninos do tráfico se insere neste grupo de produção artístico-literária, sob a modalidade de denúncia e reportagem.

Ao contrário da literatura da Shoá, o documentário não trata de uma situação histórica encerrada, e não problematiza a relação da linguagem com o real. Entretanto, não deixa de ter em comum com aquela o valor do sobreviver ao trauma. Vê-se, portanto, que a função do testemunho está para além da história individual: trata-se, sobretudo, de "narrar" a história coletiva dos banidos ("sacer") da sociedade maior. Quanto a isto, a audácia dos autores em trazer ao conhecimento do grande público a situação de desamparo e violência na qual muitas crianças brasileiras sobrevivem é exemplar: visa afetar o espectador a ponto de fazê-lo tomar consciência da necessidade de responder à violência perversa inerente aos laços sociais. 
MV Bill e Athayde declaram não querer "fazer uma análise profunda baseada em teorias para explicar o motivo desta tragédia" (orelha do livro). Entretanto o olhar que mantêm para o problema é o de dentro, de quem conheceu a miséria, de quem mora na favela, de quem tem laços afetivos com aquela comunidade excluida. Mesmo sem querer interpretar, Bill interpreta espontaneamente desde dentro do universo de significações que compartilha com os pequenos falcões. Deixa claro que é porque são invisiveis, porque ninguém os olha e escuta, que eles entram no tráfico onde têm um lugar, e conseguem assim na favela a visibilidade que não tinham antes.

O documentário é composto apenas de entrevistas. Evitou-se qualquer imagem de arquivo que pudesse insuflar a estetização da violência e da morte, em detrimento da escuta necessária, capaz de legitimar a palavra do sujeito cuja vida não the pertence. Neste sentido, os documentaristas procedem como o fez Claude Lazman no filme Shoah (1976-1985). Numa tentativa de restaurar a cena originária das vítimas, Lazman privilegiou o ouvido no lugar do olho, "fazendo falar os lugares vazios e mudos ao ritmo dos testemunhos" (SELIGMANN-SILVA, 2003, p. 145), convicto de que a palavra é o único instrumento capaz de fazer emergir o testemunho vivo do instante passado no presente. O imperativo de testemunhar faz enfrentar o buraco negro da memória da barbárie e preenchê-lo com as palavras do testemunho, deixando sem efeito todo o abuso da retórica e dos efeitos especiais (CANGI, 2003, p.147)

Já a tragédia dos nossos meninos é uma realidade cotidiana, e tão cotidiana que tende a se tornar invisivel. O efeito que Bill e Athayde conseguem, ao nos espantar com a realidade que nos expõem, se contrapõe ao mecanismo de recusa ${ }^{5}$ que, segundo Freud é sempre a primeira reação àquilo que entristece, constrange e assusta. Enquanto muitos se recusam a voltar sua atenção para a situação de exclusão social em que vivem os garotos, os documentaristas convocam o leitorouvinte a tomar consciência desta questão aviltante. Banalizar o sofrimento é uma estratégia para fugir do mal-estar e de assumir a responsabilidade pelo outro. Contrapondo-se a essa tendência, o filme permite que as vozes dos falcões sejam o testemunho vivo do instante de inserção da criança no submundo do tráfico e do banditismo.

Os depoimentos dos meninos comovem e surpreendem o espectador: Surpreenderam, com sua contundência, até mesmo MV 
Bill, que imaginava que os meninos das quadrilhas do tráfico, além de serem uma mão de obra barata, seriam relativamente pouco punidos. Sabe-se que o Estatuto da Criança e do Adolescente oferece-lhes a garantia de impunidade até os 18 anos. Entretanto, ouvir os pequenos bandidos, confessa Bill na entrevista, mostra-nos que, ao contrário, são severamente punidos, embora não diretamente pela lei. São privados de sua infância, da tranqüilidade, do sono, das brincadeiras: recebem 350.00 reais por mês para prover comida para mãe e eventualmente para os irmãos, e convivem com a consciência da vida curta a que se sabem destinados. Vêm seus próprios destinos em seus colegas: pais ainda meninos, que abandonam pela morte seus filhos ainda bebês, realimentando o ciclo de crianças abandonadas e desassistidas.

Na verdade, a maioria dos "falcões", nunca chegou a conhecer seus pais que morrem jovens servindo ao tráfico. Submetidos a esta tragédia social, sabem que a linha final de suas vidas é no máximo 18 anos e que legarão a seus próprios filhos o mesmo destino. É que a ausência de lei simbólica, a lei que sustenta as cadeias genealógicas, o laço social, e que garante os benefícios da cidadania, tornou-se o cotidiano dos "falcões". Respondendo à violência que sofrem, sem condições de avaliar moralmente os atos criminosos que cometem, vivem num paradoxo que é explicitado pela fala da mulher de um deles em seu enterro: "Matar o meu marido em nome da lei é fácil, dificil agora é criar uma lei para sustentar o meu filho" (BILL e ATHAYDE, 2006 p. 7).

O que esta situação dolorosa faz pensar ao psicanalista? Teriam as teorias psicanalíticas algo a dizer sobre a situação destes garotos brasileiros, embora, como bem lembra MV Bill, o circuito do tráfego de drogas seja internacional? Sabe-se que a teorização de Freud sobre o trauma foi reescrita por Lacan de modo a ratificar e expandir o princípio psicanalítico de inexistência de uma diferença entre psicologia individual e psicologia coletiva. Neste sentido, o trauma do nascimento, para Lacan, é nascer para um mundo de linguagem e de significantes que nos antecedem. O significante se impõe para o sujeito a advir, submetendo-o de forma absoluta.

Piera Aulanier (1975) emprega a palavra violência para conceber este processo de humanização do recém-nascido, depois de acompanhar Lacan por vários anos, e de construir uma metapsicologia própria, em cujas linhas mestras a influência de seu mestre é evidente. Violência 
da interpretação: - interpretação necessária e integrante da função materna, já que a mãe entende como pode seu bebê, e este passará a tudo entender, inclusive a si mesmo, dentro das categorias que pela mãe lhe são apresentadas, e que não dizem respeito apenas a suas particularidades, mas são também categorias que fazem parte daquela cultura da qual ela é porta-voz. A alienação aos significantes do Outro remonta necessariamente à nossa constituição, mas pode se restabelecer posteriormente, o que significa uma violência, ao contrário de estruturante, danosa à integridade do eu.

A alienação do pensamento é uma possibilidade de saída para um conflito identificatório que, segundo a autora, não se situa no campo da neurose nem da psicose, e que se impõe a partir de injunções absurdas e paradoxais da realidade, de acontecimentos que colocam em questão a capacidade do sujeito de tolerar um conflito. O Eu destrói em parte seu pensamento e sua referência a ideais, a um projeto próprio e a seu próprio futuro, alienando-se ao que é pensado por alguém mais (AULAGNIER, 1979). Nesse processo de alienação, é claro que além de alguém disposto a se alienar, é determinante que haja alguém interessado em aliená-lo, e sabemos o quanto os meninos são cooptados e seduzidos pelos interessados em dispor de seus serviços.

Assim, assumir ideais coletivos, como os do bando dos narcotraficantes, implica na suspensão de ideais próprios. O próprio chefe dos bandidos é reconhecido como a pessoa mais importante e valorizada de sua vida por um dos meninos, que assim desvela como nele encarna seu ideal. Também a adicção à droga é uma forma de escapar, pela renúncia à perspectiva de futuro e ao pensamento, a conflitos colocados por uma realidade ambiental intolerável ou louca, havendo uma continuidade entre essas duas formas de driblar as dúvidas e os conflitos identificatórios. (BERENDONK, 2005)

A alienação que se concretiza como forma de vida para os falcões é a de total escravidão aos chefes do tráfico da favela, cuja fala tem que ser obedecida sem contestação ou delongas sob pena de morte sem julgamento. Trata-se de uma forma de alienação conjuntural que é fomentada pela lei da horda, do mais forte ou do mais bem armado, que prevalece nas favelas, e das quais temos algumas notícias apenas quando o tráfico ordena aos lojistas que fechem suas portas, como às vezes ocorre em ruas da zona sul. 
Sabemos, por outro lado, que não são todos os meninos da favela que tomam o caminho do tráfico. O próprio MV Bill, em sua entrevista, refere-se, entre alegre e tímido, à zanga de sua mãe, que o chamou de irresponsável quando ele, sentindo-se perseguido em conseqüência do seu vídeo clipe estar sendo considerado pela polícia como uma apologia às drogas, comentou que, se tivesse que morrer por sua obra, aceitaria essa sina. A força do voto materno que o quer vivo talvez o tenha influenciado em sua busca pela música e pelo ativismo político ao invés do crime.

Já os meninos menos afortunados, nascidos de uma mãe criança, sozinha e desamparada, talvez não tenham encontrado acolhimento, alegria nos olhos maternos, um lugar como objeto do desejo da mãe que pudesse colocá-los no caminho do amor à vida e à criação.

A relação da mãe com a criança, fundamental na constituição do seu psiquismo, e que deixará nele as marcas mais fundamentais, depende muito do ambiente em que essas primeiras experiências de interação ocorrerão. Um ambiente patogênico é tão importante na determinação de como se dará essa relação, que Andre Green apresenta como sendo a causa da depressão infantil, a relação primária com alguém que ele chama de "mãe morta". Essa mãe não está efetivamente morta, mas está deprimida, vivendo um luto por perdas que sofreu ou que ainda sofre, por condições adversas que tem que enfrentar em sua própria vida. Embora possa cuidar do seu filho, está absorta em si mesma, triste, silenciosa, e sem interesse na criança. A falta de vitalidade e de investimento amoroso no filho em conseqüência de luto e depressão é uma conseqüência muito possível da falta de uma estrutura familiar que possa apoiar uma mãe menina em sua maternagem. A imagem que a criança terá de sua mãe deprimida será a de uma "figura distante, átona, quase inanimada"(GREEN, 1980.p. 239).

O próprio desejo de viver de cada um tem sua origem no desejo materno de que seu filho viva, desejo com o qual este se identifica. Em um artigo pioneiro de Sándor Ferenczi, "A criança mal acolhida e sua pulsão de morte" (FERENCZI, 1929), já se encontra desenvolvida essa idéia de que a pulsão de morte tem sua origem na forma como a chegada da criança é recebida. A partir de sua experiência como médico num hospital militar e também como analista, o autor se dispõe a compreender a gênese das tendências inconscientes de autodestruição. 
A atração pela morte pareceu-lhe ter origem na captação, por parte da criança, de sinais de aversão e de impaciência por parte da mãe. A hostilidade materna mina, no infante, a vontade de viver.

Certas doenças, como a asma brônquica e a anorexia, incidiam, na observação do analista, em pacientes que lutavam contra tendências suicidas. Levanta então a hipótese de que provavelmente as crianças recebidas sem carinho morrem com mais facilidade e, quando sobrevivem, conservam uma atitude pessimista e desconfiada, e se vêem tentadas a morrer a qualquer percalço em suas vidas, mesmo quando conseguem compensar essa tentação às custas de um esforço permanente de vontade.

A interpretação de Ferenczi é a de que encontrar, ao nascer, essa mensagem materna de rejeição, de desinteresse, de falta de alegria, que os bebês captam mesmo quando é inteiramente inconsciente para as próprias mães, é uma situação que viria a reforçar a pulsão de morte da criança, já que equivale a um mandato como - suma, desapareça! que a criança irá incorporar por identificação na formação do seu supereu.

É importante ressaltar que o amor é, para Freud, sempre ambivalente, que alguma hostilidade sempre está presente no amor materno. Efetivamente, não há amor integral e perfeito, e a pulsão de morte jamais deixará de encontrar terreno para se constituir por identificação com a hostilidade do adulto que se eterniza no supereu. Mas as circunstâncias ambientais são profundamente importantes na determinação da maneira como cada mãe se posiciona em relação a seu filho. A mãe desprotegida pela família e pelo Estado não pode deixar de receber seu filho de forma relutante, quando as condiçōes mínimas de conforto e apoio para a maternagem the são negadas.

Nas comunidades em que moram os meninos-falcões, o Outro como o Estado, que poderia e deveria thes oferecer proteção, como o atendimento nas áreas de saúde educação e segurança, só o faz de forma muito precária, atuando também como una "mãe morta". Pouco thes resta além da fome e do descaso. Na favela, deserdada e esquecida pela lei da cidade, a lei que predomina é a do tráfico. Evidentemente que toda esta problemática afeta, diretamente, a constituição narcísica do sujeito. Abandonados, sem referências ou apoio, os meninos se drogam . Diz um deles: "Não fico triste, tô sempre se drogando". Como observa Kehl, no "lugar desse nada, a droga instala um vazio mais 
suportável"(KEHL, 2006). Mas a própria realidade inexorável, implacável e traumática em que vivem, perpetua-se neste gozo assexuado e "autista", com que buscam dribá-la.

Narcotizados, os jovens enfrentam a única opção que é oferecida aos que não contam com um mínimo de estrutura familiar e de recursos que lhes permitam ir à escola. $\mathrm{O}$ tráfico permite não só sustentar a família miserável como também lhes fornece visibilidade, códigos, leis, signos, enfim, parâmetros para uma certa orientação subjetiva que até então não conseguiram encontrar. Os custos são altos. As quadrilhas exigem dedicação e obediência integral, roubando dos falcões a infầncia e quaisquer outras oportunidades, em troca de um lugar para uma criança que não possuía nenhum.

A psicanálise, apesar de não apreender a totalidade de qualquer objeto sociológico, nem tampouco o conjunto das motivações atualmente em ação em nossa sociedade, pode esclarecer "tensões relacionais que parecem desempenhar em todas as sociedades uma função basal, como se o mal-estar da civilização desnudasse a própria articulação da cultura com a natureza"(LACAN, 1950/1985, p. 129). A fusão da miséria com a droga está ligada a uma cadeia de causas extremamente óbvias - falta de recursos econômicos, falta de educação, falta de pai e ou de mãe, excesso do uso de drogas, até a lógica instrumental dos traficantes e a do capitalismo sem escrúpulos. São causas a serem atacadas com urgência, não fosse a morosidade de um país nas mãos dos que fogem compulsivamente à responsabilidade por seus atos.

Como cidadãos, o que fazer para manter acesa a chama de horror que nos causou o documentário, para não transformá-lo em dejeto, isto é, em mais um show da vida de nossa sociedade de espetáculo? Talvez aprender a escutar as vítimas da repressão e da negação absoluta do direito. Somos devedores da iniciativa freudiana de escutar o outro e, dentro deste modelo, as vozes dos "falcões" tornam-se muito mais importantes do que a fala de muitos políticos e o saber dos doutores.

Que faltem aos meninos oportunidades de sonhos que não se vinculem ao tráfico é evidente. O documentário nos mostra crianças muito pequenas brincando de bandidos, mostrando grande intimidade com esse universo. Fingem cheirar cocaína e fumar maconha, usando folhas de eucalipto, trocam tiros de brinquedo, e encenam queimar um X9. Mesmo ainda mais jovens, as crianças já atestam o peso da presença esmagadora do tráfico na favela e sua influência sobre elas. Uma jovem 
mãe conta, muito angustiada, que seu filho, de menos de três anos, já sabe que existe o tráfico e brinca, fingindo disparar uma arma com o dedo. Se a brincadeira permite apreender a realidade e ampliar o campo simbólico, como Freud observou, a repetição na brincadeira é também um modo de tentar controlar experiências assustadoras, e revivê-las de modo menos passivo do que quando elas ocorreram - quando menos se esperava. No caso das crianças da favela, o brincar reencena o cenário doloroso e assustador do crime em meio à mais inocente infantilidade.

Sabemos que aumenta, cada vez mais, o número de crianças aliciadas pelo tráfico. Parodiando o repórter Blake Morrison, ao cobrir o julgamento de 3 meninos que dão uma surra e matam um mendigo na cidade de Chicago, nas favelas brasileiras "a infância não é mais lugar para criança" ( Blake Morrison apud Arthur NESTROVSKI, 2000, p. 189). O tráfico alicia os meninos, como vimos, oferecendo-lhes trabalho, remuneração, o prestigio de que desfrutam os que possuem uma moto, um lugar de visibilidade. Para competir com esta organização perversa, a sociedade teria que lhes oferecer projetos alternativos através do esporte, das artes, dos programas profissionalizantes, de caminhos para uma vida melhor. É fundamental thes dar essas condições para que essas crianças possam reconhecer o direito à vida, para que cheguem a avaliar suas próprias vidas como algo de valor, que merece zelo. Para concluir, nada melhor do que as palavras de MV Bill de esperança na solução do problema. "Se eu fosse o general de um exército faria uma grande invasão nas favelas do Brasil, com as armas da saúde, da educação, da cultura, do conhecimento, da oportunidade, da visibilidade, do desenvolvimento"(Bill, 2006/2007).

\section{Notas}

1 A origem do Rap remonta à Jamaica, mais ou menos na década de 60 quando surgiram os Sound Systems, que eram colocados nas ruas dos guetos jamaicanos para animar bailes. Esses bailes serviam de fundo para o discurso dos 'toasters', autênticos mestres de cerimônia que comentavam, nas suas intervenções, assuntos como a violência das favelas de Kingston e a situação política da llha, sem deixar de falar, é claro, de temas mais prosaicos, como sexo e drogas. 
2 Em seu livro Homo Sacer. O poder soberano e a vida nua (2002), Giorgio Agamben recorre a um certo giro genealógico para destacar a figura obscura e esquecida do homo sacer, uma figura talhada no interior do antigo direito romano, e demonstrar sua absoluta atualidade como representação da passagem da vida humana à vida nua, a vida descartável.

3 Em "Testemunho e a política da Memória: o tempo depois das catástrofes", Seligmann-Silva, a partir do estudo de Benveniste sobre testemunho, aborda dois sentidos para a noção de testemunho. Testis, aquele que assiste como terceiro (terstis) a um caso em que dois personagens estão envolvidos, e Superstes, que designa a testemunha que é, ao mesmo tempo, sobrevivente. ." "O manter-se no fato" do supereste remete à situação singular do sobrevivente como alguém que habita na clausura de um acontecimento extremo que o aproximou da morte". (Seligmann-Silva, 2005, p. 81)

4 Em trabalho apresentado no "Encontro Nacional Trauma e Memória", na PUC-Rio em junho de 2007, ocasião em que também apresentamos o trabalho em questão, Selligmann-Silva traça um paralelo entre a cena do testemunho e a da clinica psicanalítica para responder à questão do testemunho em meio, e não após as situações traumáticas. Considera que a cena do testemunho, se o testemunho de fato acontece, é sempre e paradoxalmente externa e interna ao evento narrado. Interna porque em certo sentido não existe, conforme Freud demonstrou em Para além do Princípio do Prazer, um "depois" absoluto da cena traumática - nada é recalcado. Por outro lado o testemunho, diz o autor, é externo àquela cena traumática na medida em que ele cria um local meta-reflexivo. O testemunho exige um certo distanciamento e portanto é terapêutico.

s Estamos nos referindo aqui ao mecanismo de defesa de recusa - Verleugnung - da realidade que também se costuma traduzir por renegação ou desmentido. Toda a cultura se institui pelo recalque e pela recusa. Se o primeiro se volta contra um desejo que causa um conflito, a recusa da realidade permite conservar a satisfação pulsional, que não é, portanto, recalcada, e velar a realidade, embora de forma diferente da perda da realidade na psicose. Verleugnung é uma forma 
de lidar com uma contradição, uma incompatibilidade entre o que se deseja e o que a realidade apresenta. Neste sentido o trabalho dos documentaristas levanta a recusa que opera em nossa sociedade $\mathrm{em}$ reconhecer e extrair as consequências da lastimável situação dessas crianças.

\section{Referências bibliográficas}

AGAMBEM, Giorgio (2002) Homo Sacer. O poder soberano e a vida nua 1, Belo Horizonte: Editora UFMG.

AULAGNIER, Piera (1975) A violência da interpretaçào. Do pictograma ao enunciado. Rio de Janeiro: Imago.

AUlAGNIER, Piera (1979) Les Destins du Plaisir - aliénation, amour, passion. Paris: Presses Universitaires de France.

BERENDONK, Eduardo Coutinho (2005) Gozo, Logo Existo, Em Busca do Pensamento - Um estudo psicanalítico sobrc as drogadicções. Tesc de Doutorado PUC-Rio: http://www.lambda.ele.puc-rio.br/cgi-bin/db2www/ PRG_0490.D2W/INPUT?CdLinPrg=pt

BILL, MV; ATHAYDE, Celso (2006) Falcão - meninos do tráfico, Rio de Janeiro: Editora Objetiva e Central Única das Favelas (CUFA)

BILL, MV (2007) Entrevista 19 de março de 2006: Rapper lança documentário, livro e álbum sobre meninos do tráfico. Diário Vermelho, 16 de julho de 2007: http://www.vermelho.org.br/diario/2006/0319/ 0319 mubill-falcao.asp

FERENCZI, Sándor. (1929/1992) A criança mal acolhida e sua pulsão de morte. In: Sándor Ferenczi - Obras Completas, v. IV, São Paulo: Martins Fontes, p.47-52.

CANGl, Adriản (2003) lmagens do horror. Paixões tristes. In: SELIGMANN-SILVA. M.(org.) História Memória e Literatura, p. 141 172.

GREEN, André (1988) A mãe morta. In: GREEN, A. Narcisismo de Vida, Narcisismo de Morte. São Paulo, Escuta, p. 239-73 
GULAR; Ferreira (2006) Crime-primeiro emprego, Folha de SP Ilustrada 02 de abril de 2006.

FREUD, Sigmund (1930/1976). "Mal-estar na Cultura", Obras Completas, Buenos Aires: Amorrortu Editores.

KEHL, Maria Rita. As Asas Quebradas, Folha de São Paulo, Caderno Mais! 26 de março de 2006.

LACAN, Jacques (1950/1985) "Funciones del psicoanálisis en criminologia" (1950). In: Escritos. Buenos Aires Siglo XXI.

NESTROVSKI, Arthur (2000) Vozes de Crianças, In SELIGMANNSILVA, M. e NESTROVSKI, Arthur (orgs.) Catástrofe e Representação, São Paulo: Escuta, p. 185-206.

SELIGMANN-SILVA, Márcio (2003) História, Memória, Literatura. O testemunho na Era das Catástrofes. São Paulo: Unicamp.

SELIGMANN-SILVA, Márcio (2005) Testemunho e a política da 74 memória; o tempo depois das catástrofes . Projeto História, São Paulo (30) p. 71-98, junho de 2005 .

http://www.pucsp.br/projetohistoria/downloads/volume30/04-Artg(Marcio).pdf 